\title{
Is the War on Poverty Attacking Mental IIIness?
}

\author{
John M. Riley, Ph.D.* \\ Phillip A. Fellin, Ph.D.
}

ABSTRACT: Based on a 2-year study of Office of Economic Opportunity (OEO) programs in a large urban center, this paper examines the potential of Community Action Centers for serving low-income clients with emotional problems. The processing, referral and follow-up patterns of the indigenous counseling staff are described. Strategies for mental health agencies are developed for enhancing their links with these programs and increasing the impact of the War on Poverty on mental illness.

The apparent relationship between low economic status and elevated incidence and prevalence of mental illness has become increasingly apparent to mental health practitioners during the past 10 or 15 years. The New Haven study in 1958 (Hollingshead \& Redlich, 1958) following by the Midtown Manhattan Study in 1961 (Srole, Langner, Michael, Opler, \& Rennie, 1961) were both widely read and quoted by mental health professionals. The findings of these and other large research efforts indicated that there was a direct relationship between the experience of poverty and a high rate of emotional disturbance as well as differential use and availability of treatment modes and facilities by different social classes. Michael Harrington more dramatically made the same point and reached a still wider audience in his discussion of the impoverished in America (Harrington, 1964). He depicted mental illness as an important concomitant of poverty in this country.

Following these studies, and undoubtedly in response to them, some mental health programs developed with the specific aim of reaching and serving low-income groups. A body of literature has developed, exemplified by The Mental Health of the Poor (Reissman, Cohen, \& Pearl, 1964), that documents the failure of existing service delivery systems and treatment methods to meet the needs of the poor and describes new programs aimed at low-income clients.

At the same time the community mental health movement, with its emphasis on serving total communities or in its jargon "catchment

* Dr. Riley is Dean, School of Social Work, Barry College, Miami Shores, Florida, 33161. Dr. Fellin is Dean, School of Social Work, University of Michigan, Ann Arbor, Michigan, 48104. The research reported in this paper was supported in part by the Office of Economic Opportunity (CG 8793). The study was under the direction of R. D. Vinter, R. C. Sarri, and F. A. Fellin of the University of Michigan. The findings presented in this paper were presented at an American Orthopsychiatric Association Annual Meeting, San Francisco, March, 1970. 
areas," the identification of populations at risk, primary prevention, and the examination of service delivery systems, further focused the attention of mental health groups on the emotional problems of low-income groups.

With these developments on the mental health scene, it is not surprising that the Economic Opportunity Act of 1964 was greeted with enthusiasm. The War on Poverty was hailed by many mental health workers as a major new force for lowering the incidence and prevalence of mental illness. Based on existing research, it was easy to assume that by abolishing poverty we would abolish mental illness-that a war on poverty was a war on mental illness.

Our enthusiasm was additionally stimulated since the programs of the Office of Economic Opportunity (OEO) were designed to hire and utilize large numbers of the indigenous poor as front-line workers. Mental health programs had been in the forefront in the use of indigenous nonprofessionals in treatment programs and a romantic view had developed concerning their unique skills and effectiveness. The extreme view was "if the traditionally trained professional cannot cure them, the indigenous worker can."

The impact of the War on Poverty on mental illness was anticipated at several levels. It was believed that by raising individuals out of poverty the risk of illness would be lowered. This could be accomplished both by hiring the poor within the OEO agencies themselves as well as through the job training and placement services of the Community Action Centers. In addition to such primary prevention efforts, it was anticipated that the programs would provide early case finding and treatment services as well as become referral sources for existing mental health facilities.

It may be too soon to evaluate the effect of the War on Poverty in terms of primary prevention of mental illness. However, it is possible to examine the practice of OEO Community Action Centers and evaluate their ability to provide secondary and tertiary prevention.

This paper examines the potential of the Community Action Centers for serving low-income clients with emotional problems as well as their functioning as case finders and referral sources for mental health agencies. It is based on empirical research findings from a systematic 2year study of OEO programs in a large urban area. Data were collected from personnel in four neighborhood Action Centers and included observations of client-worker transactions, abstraction of file data, questionnaires administered to line and administrative staff, and interviews with supervisory staff, area administrators, and program executives. Although limited to one geographical area, observations and communications with staff in other OEO programs suggest that our findings would be supported in many community action programs. 


\section{THE COMMUNITY ACTION CENTER}

Community Action Centers are in most respects the key units of the local antipoverty programs. It is in the centers that the poor and their needs come to be identified, and it is from the centers that the poor may be referred to a multitude of community services. Each Action Center in the metropolitan area we studied is located in a "target area" which is characterized by high rates of unemployment, low household income, substandard housing, infant mortality, crime, and mental illness.

Conceptually, we viewed the Action Centers as people-processing organizations. In our research we focused on the interviewing and counseling units of the centers where the problems and needs of clients are explored by counselors. They were observed to be archetypes of processing organizations, due to their concern almost exclusively with rapid movement of persons to new or modified social statuses. There was little evidence of "people-changing" technologies in these units-that is, activities directed toward changing specific behavior, attributes, or perspectives of individuals.

Our study of the interviewing and counseling units allowed us to observe how clients were processed-that is, to identify decision junctures and alternatives, and to examine the behavior of staff at each of the junctures. Our observations of behavior at several decision junctures in the Action Centers are now presented.

\section{Information-Reception}

Persons entered the Action Center by presenting themselves physically at the door or by telephone. Some emergencies and crises were handled by telephone, but whenever possible, persons were urged to come to the center. The receptionist at the information desk occupied an important position in the initial screening of all who entered, and was usually quite diligent about intervening in the initial routing of persons. The receptionist often exercised considerable discretionary authority over the movement of cases but was seldom subject to any supervision.

\section{Intake}

After completing a "routing slip," which provided minimal information about the potential client and his request, the receptionist referred the applicant to "Intake." Counselors interviewed clients individually using the intake form as a structural outline for the interview. This form usually required 20 to 30 minutes to complete and frequently provoked hostile reactions from clients who could not understand why it had to be completed regardless of the request. A literal, and sometimes, religious adherence to the intake form was observed in 
many of the counselor-client transactions. Pressure to complete the intake form hampered the worker when he became more concerned about completing the form than in listening to or addressing the client's problems. Completion of the basic intake form in a routinized manner appeared to be the most significant factor in the counselor-client transactions at this phase in case processing.

\section{Referral}

The large majority of clients were seen only once at the Action Center despite the complexity of their problems and the difficulties likely in effecting successful referrals. Case processing from intake to referral in the typical case took place in one interview which lasted about a half hour.

The centers lacked any formal documents that specified the intake criteria, informational requirements, and so forth, of external agencies to which clients might be referred. Counselors relied almost exclusively on elaborate informal informational systems and learned the intake criteria of other agencies by repeatedly testing them with clients having different characteristics. There was no formal intelligence system to provide counselors or supervisors with adequate up-to-date information about potential services and markets for clients. That knowledge of external referral agencies was limited is apparent from the fact that in the counseling interviews that we observed in which clients were referred approximately $75 \%$ were referred to internal agencies and only $25 \%$ to external agencies. Nearly $50 \%$ of these cases were referred to medical services and yet only one case was referred to an external medical agency.

\section{Follow-Up}

Although the parent OEO organization gave high priority to follow-up, very little systematic activity in this area was observed. Our observations indicated that overall the centers had little or no information about the outcome of referrals. Furthermore, little was done when it was known that an unsuccessful referral occurred to re-establish contact and provide other services to clients.

\section{CLIENT CAREERS}

In addition to participant observation of case processing in two Interviewing and Counseling units, our research also involved systematic observation of 182 counselor-client transactions, and the abstracting of official information from 575 case files. These data provide information about the processing itself and of the consequences for clients.

Most clients were referred to the center by friends or relatives. The lack of viable referral relationships with other agencies is readily appar- 
ent, for $10 \%$ or less of the clients came to the center from other agencies. Observations of client transactions indicated that clients were truly multiproblem. They often encountered difficulties in employment and financial management, suspension of income by welfare departments, securing assistance from welfare agencies, child care management, housing, and serious personal problems. In examining the records of the exploration process, however, it appeared that the counselor directed his questions to the client only and was not concerned about his family. In view of the fact that more than half of the clients were females with dependents, lack of attention to the family situation was particularly significant.

In those cases in which our researchers observed counselor-client transactions, posttransaction interviews were held with the counselors. Counselors reported that they perceived clients had additional problems in $80 \%$ of the cases at one center and $92 \%$ at the other center. When asked why they did not attempt to specify or deal with these problems, the most frequent reply from the counselors was that they lacked the appropriate relationship with the client or they had no resources to deal with the problems so that it was futile to consider them.

In regard to referrals, in about $35 \%$ of the cases the client was merely provided with a routing or referral slip. The case files did not report many instances of personal contact or informal referral, although research staff observed considerable informal behavior in this area for selected clients. The large majority of clients $(78 \%$ in one center, $84 \%$ in the other) received only one referral for service; and in $62 \%$ of the total number of cases from both centers there was no information about feedback from the referral. Further, very few counselors had information about the length of time that clients might have to wait for a final decision about the referral despite the fact that this question was frequently asked by clients.

Despite the recognition that they were not dealing directly with many of the problems the client had and also that they had severely limited information about the referral sources, the counselors were optimistic about their ability to deal with clients' problems. Over $70 \%$ reported in interviews that the problems could be dealt with satisfactorily. This finding provides evidence of a widespread delusion often observed in the Action Centers. Although many of the staff were aware that their clients had many problems and limited resources and that many of the staff referrals would not be successful, they still were very optimistic about their ability to deal with their clients' numerous problems.

Our research staff noted at least two competing styles in counselors' work with clients; on the one hand some counselors were very formal, filled out forms continuously, and provided the client with various routing and referral slips in an impersonal manner. On the other hand some counselors seemed to identify with the client and tried to understand and deal with his problems informally rather than formally. They 
offered advice, told the client informally about jobs available and whom to contact and tended to accept the client's definition of his problem although other agencies may have rejected it. They also invited clients to call or return if they had difficulties.

\section{COUNSELOR PERSPECTIVES}

In addition to our picture of client processing in Commmunity Action Centers, we were also interested in the counselors' perspectives about the clientele and their problems, their own roles and activities as helping persons, and the goals of the agency.

The staff's view of the genesis of their clients' problems were elicited by their rating of various statements regarding the causes of poverty in America. They strongly agreed with statements that placed responsibility for their clients' problems outside the individual's control and responsibility - for example, in the failure of society to provide adequate services such as good schools, health facilities, and housing. Conversely, they tended to reject statements that placed responsibility for their clients' problems on individual failures or inadequacies that called for changes in the attitudes, values, or behavior of the client.

It is therefore not surprising that the counselors overwhelmingly viewed their job primarily as obtaining resources and services for clients rather than counseling them regarding personality or behavioral deficiencies. Data in this area were obtained through a series of paired statements regarding the expected activity and goals of counselors. In every instance the vast majority selected activities whose objective was the provision of information on available services rather than individual change goals. For example, $96 \%$ of the 130 counselors responding indicated they should "Find out what some other resource can do to help the client" and only $4 \%$ felt they should "Convince the client to change some of his behavior and attitudes." In short, in all measures the majority of the line counselors perceived processing activities as the objectives of their program and in fact spent only $17 \%$ of their time in counseling clients.

These data support our characterization of the Community Action Center as a people-processing organization rather than a treatment organization. However, we also elicited responses to statements on how workers should handle clients. In contrast to our findings regarding perspectives on program objectives and workers' current activities, the workers displayed a strong preference toward treatment-oriented activities. For example, $82 \%$ of the staff disagreed with the statement, "There is really no need to explore deeply the client's situation in order to find out his problem"; $72 \%$ agreed with the statement, "There is a great deal of difference between what the client says and what his real problem is." These preferences of workers, however, are in direct contrast to our observations of actual client-worker transactions. 
GENERAL PROBLEMS OF

COMMUNITY ACTION CENTERS

To summarize, our research suggests several general problem areas in the operations of the Community Action Centers. To the extent that our findings can be generalized to other centers, recognition of these factors is critical for any mental health agency that anticipates developing a mutually productive relationship with a Community Action Center in a common attack on mental illness.

\section{Deficiencies in Information and Decisional Systems}

The Action Centers did not have a viable information system which would provide data about the client population, about operational patterns, market exchanges, or outcomes. The lack of such a system hampered decision makers at all levels of the organization, from intake counselor aides to program heads and executives. For example, lack of adequate records on assignments limited the role of supervisors in monitoring the work of line staff. The primary emphasis of the system in operation was on serving external reporting requirements, and because these were not perceived as relevant to operative and monitoring staff, they were viewed as meaningless. There was an overemphasis on "numbers" as criteria for measuring effectiveness and efficiency, and a minimizing of goal outcomes or costs as criteria. Staff then came to stress the number of client contacts rather than the nature of the contact or the results of their actions.

\section{Deficiencies in Operational Patterns}

The interviewing and counseling units observed in this research lacked viable technologies for achieving the end that they sought. The lack of systematic information inhibited the development of technologies as did ambiguity in goals and certain ideologies and beliefs of staff in policy making positions. The Community Action program was established to be innovative, and one of the ways through which innovation was to be accomplished was through employment of indigenous persons from the neighborhood as staff at several levels in the organization. There appeared to be an unverified assumption about the knowledge and capability of these persons to solve intuitively the problems of the poor. The mechanical use of the intake processing form appeared to be more the result of organizational structure than of staff characteristics, but it does illustrate that staff characteristics alone are unlikely to handle major organizational problems. The issue to be resolved was how staff with certain characteristics could be effectively used, not whether they should be used.

Staff supervision-its control and development-was another major problem in the Community Action Centers. Given the large volume of clients and the initial capability level of the personnel, a staff develop- 
ment program was sorely needed. This problem was aggravated by the frequent lack of authority on the part of supervisors and administrators. If staff performance was less than desired, it was often stated that they had to be viewed as clients as well as staff. Furthermore, because of political and other types of influence, supervisors had little authority to censure line staff. There were no routinized supervisory arrangements and little coordination of worker activities. Supervisors had no formal structure for supervision or consultation with individual staff, so that assistance was given on an ad hoc basis. The passive role of most supervisors was encouraged by the stress on the use of indigenous workers who were allowed to learn on the job and continue to make mistakes without disciplinary action. Because of the operational patterns, client careers were generally observed as very brief and often truncated. Most clients were seen only once, in a brief interview that focused only on the initial problem presented by the client. The lack of feedback information prohibited an accurate assessment of the extent of this problem but our observation of worker-client transactions indicated that clients often had multiple problems that would require complex intervention procedures if satisfactory outcomes were to be achieved. Furthermore, the orientation of workers to view their clients' problems and their resolution in terms of the availability of community resources discouraged them from being sensitive to personal adjustment problems of an intrapsychic or interpersonal nature.

\section{Relationships to External Environment}

A third problematic area concerned the relationship of the center staff to the external environment. Exchange relationships for the referral of clients were extremely limited. Agencies most frequently used for referral were those located within the same building. The counselors were ignorant of external agencies to which clients could be referred or if they knew about an agency they might not know its intake criteria and procedures. This limitation was particularly apparent in the counselors' handling of multiproblem clients. There was little consultation with external agencies. In fact, in 262 cases only five examples of consultation were identified.

Additionally, although one important aspect of the supervisory role was understood to involve identification of gaps in services and the development of referral resources, supervisors also were found to be acquainted mainly with programs within OEO and not with outside agencies. The supervisors had no systematic contacts with outside resources or a strategy for fulfilling this aspect of their role. Similarly, the area administrators spent less than $10 \%$ of their time in developing or maintaining relationships with organizations outside the centers. Thus our analysis indicates that clients did not receive the "coordinated public and private agency services" which the OEO program sought to achieve. 


\section{IMPLICATIONS FOR MENTAL HEALTH AGENCIES}

Our findings suggest that the Community Action Centers are not waging an effective war on mental illness. They are not recognizing and treating as such the mental health problems of their clients nor serving as effective case finders or referral sources for mental health agencies. In fact the vast majority of the counseling staff reported that they had little or no contact with medical facilities or other community agencies that offer personal counseling. Furthermore, they felt they received little or no cooperation from such agencies when they did contact them. This perception, whether based on reality or not, discourages the centers from aggressively seeking a systematic referral system between themselves and mental health facilities. Additionally, our data clearly points out that the center staffs do not have a strategy for developing and formalizing linkages with any external agencies.

The initiative for forming such interorganizational links must come from mental health groups. Because of the large number of clients processed by the centers and the brief interaction between the clients and counselors, such referral systems will need to be simple and efficient. The receiving mental health agencies will need to spell out their admission criteria clearly, to anticipate a proportion of inappropriate referrals, to respond quickly to requests for service, and to insure that their treatment technology is applicable to low-income groups. Finally, the mental health agency will need to assume responsibility for feeding back data regarding their experience with the referred clients.

The preference of counselors toward more treatment-oriented activities suggests an additional opportunity for mental health agencies to work with the Action Centers in a common attack on mental illness. The need for additional inservice training for the counselors was apparent. In view of the current interest within the mental health professions regarding consultation, the centers offer fertile ground for such efforts.

Our observations suggest that most of the staff are highly motivated to serve their clients and eager to increase their skills. Mental health practitioners could assist them in a variety of ways. Through individual consultations as well as group training sessions they could help upgrade the counselors' general interviewing skills. Training in the recognition of clients with emotional problems and their handling of these clients within the centers' usual processing system would enhance the effectiveness of the counselors in dealing with their clientele. Consultation could also be provided regarding the process of referral to mental health agencies as well as around specific clients who may need such referral. Mental health consultation could also be made available to administrative staff around the complex personnel and staff management problems confronting the centers. 
Long-range payoff from such consultation efforts is supported by the data regarding staff turnover. We found that $63 \%$ of the total staff had been with the agency 2 years or more and $76 \%$ of the counselors had equivalent tenure. Additionally, most of these in supervisory positions indicated that they began as line workers and then were promoted within the agency. Successful inservice training efforts, therefore, would produce benefits over a long period of time. The counselors receptivity to training is supported by data collected regarding their previous educational attainments. Approximately $70 \%$ of the staff had completed secondary school and had some college or specialized postsecondary school training.

Obviously the development of such relationships and consultation programs will not be easy. Within the centers that we observed, a clear bias existed against "professionals" and a skepticism regarding the effectiveness of established treatment agencies. As we have pointed out, however, there are also forces that will facilitate the development of productive interorganizational ties. It is up to the mental health establishment to make the effort, if we want the War on Poverty to be a part of a war on mental illness.

\section{REFERENCES}

Harrington, M. The other America. New York: MacMillan, 1964.

Hollingshead, A. \& Redlich, F. Social class and mental illness. New York: Wiley, 1958.

Riessman, F., Cohen, J., \& Pearl, A. (Eds.), Mental health of the poor. New York: The Free Press, 1964.

Srole, L., Langner, T., Michael, S., Opler, M. \& Rennie, T. Mental health in the metropolis. New York: McGraw Hill, 1961. 